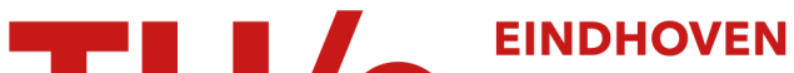 UNIVERSITY OF TECHNOLOGY
}

\section{Current understanding of the deformation of latex particles during film formation}

Citation for published version (APA):

Visschers, M., Laven, J., \& German, A. L. (1997). Current understanding of the deformation of latex particles during film formation. Progress in Organic Coatings, 30(1-2), 39-49. https://doi.org/10.1016/S0300-

9440\%2896\%2900652-2, https://doi.org/10.1016/S0300-9440(96)00652-2

DOI:

10.1016/S0300-9440\%2896\%2900652-2

10.1016/S0300-9440(96)00652-2

Document status and date:

Published: 01/01/1997

\section{Document Version:}

Publisher's PDF, also known as Version of Record (includes final page, issue and volume numbers)

\section{Please check the document version of this publication:}

- A submitted manuscript is the version of the article upon submission and before peer-review. There can be important differences between the submitted version and the official published version of record. People interested in the research are advised to contact the author for the final version of the publication, or visit the $\mathrm{DOI}$ to the publisher's website.

- The final author version and the galley proof are versions of the publication after peer review.

- The final published version features the final layout of the paper including the volume, issue and page numbers.

Link to publication

\section{General rights}

Copyright and moral rights for the publications made accessible in the public portal are retained by the authors and/or other copyright owners and it is a condition of accessing publications that users recognise and abide by the legal requirements associated with these rights.

- Users may download and print one copy of any publication from the public portal for the purpose of private study or research.

- You may not further distribute the material or use it for any profit-making activity or commercial gain

- You may freely distribute the URL identifying the publication in the public portal.

If the publication is distributed under the terms of Article $25 \mathrm{fa}$ of the Dutch Copyright Act, indicated by the "Taverne" license above, please follow below link for the End User Agreement:

www.tue.nl/taverne

Take down policy

If you believe that this document breaches copyright please contact us at:

openaccess@tue.nl

providing details and we will investigate your claim. 


\title{
Current understanding of the deformation of latex particles during film formation
}

\author{
Marcel Visschers ${ }^{a, *}$, Jozua Laven ${ }^{i}$, Anton L. German ${ }^{\mathrm{b}}$ \\ "Deparment of Colloid Chemistry and Thermodvamies, Faculty of Chemical Enginecring and Chemistry, Eindhoven University of Technology, \\ PO Box 513, $5600 \mathrm{MB}$, Eind hoven, Notherlands

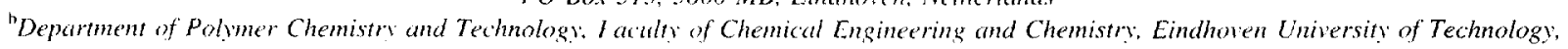 \\ PO Box 513.5600 MB. Eindhowen. Netherlands
}

Received 12 December 1995: ikcepted 22 March 1996

\begin{abstract}
This article reviews models of polymer particle deformation in film formation. Dillon et al. modelled polymer particles as viscous bodies whose surface tension provides the main driving force for particle deformation. In Brown's alternative model, deformation is driven by capillary pressure due to water evaporation and opposed by the elastic force of the polymer itself. Brown, however, assumes the area on which capillary and deformation pressures act to be equal and the particles to be elastic rather than visco-elastic. The first assumption is addressed by Mason and the second by Lamprecht. Brown, Mason and Lamprecht modelled the polymer particles response as the response of two non-attracting spheres pressed together. Kendall and Padget followed an alternative approach using the JKR theory thus incorporating the van der Waals attraction. The existence of a sharp transition in the film forming qualities near $T_{\mathrm{g}}$ is predicted by these theories through a sharp change in the elastic modulus. The predicted inverse proportionality for the particle radius is not observed experimentally. Experiments performed by Sperry et al. cast further doubt on the applicability of these theories. Keddie et al. propose a new approach to particle deformation. According to them transparent films can either be obtained along an 'easy' route, by particle deformation due to capillary forces. or along a hard' route. by particle deformation due to other surface forces; e.g. the polymer/water interfacial tension, the polymer/air surface tension or the forces due to residual water left between the particles. (C) 1997 Elsevier Science S.A.
\end{abstract}

Keywords: Film formation; Latex: Deformation: Coalescence; Capillary pressure

\section{Introduction}

Nowadays, a trend is apparent to replace conventional solvent-based coatings with waterborne ones. In general, those waterborne coatings consist of pigment (e.g. $\mathrm{TiO}_{2}$ ). polymer particles (binder), water (solvent) and additives. To facilitate the understanding of the mechanism of film formation, most researchers have focused on model systems; mostly polymer particles suspended in water (latex). In this article we are mainly interested in the film formation of those latexes.

If one applies latex onto a substrate and subsequently dries it below a certain temperature, the resulting film will consist of a non-transparent, powdery film. This opacity

\footnotetext{
*. Corresponding author.
}

suggests that there are still many residual voids left within the film, capable of scattering incident light. However, if one dries the latex above this temperature, the result will be a homogeneous, transparent film. This apparent critical temperature is called the minimum film forming temperature (MFFT). Since there is virtually complete water evaporation in both cases, the existence of the MFFT indicates that, apart from the evaporation of water, another process is involved in film formation: the spherical polymer particles deform to touching dodecahedra, leading to the disappearance of boundaries within the film. This process is evidently driven by a reduction of the interfacial energy; it is called coalescence. It is depicted in Fig. 1. The term coalescence should not be confused with the gradual coalescence as introduced by Voyutsskiì [1]. The latter is essentially the final part of coalescence in which the poly- 


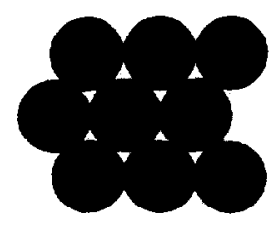

Before coalescence

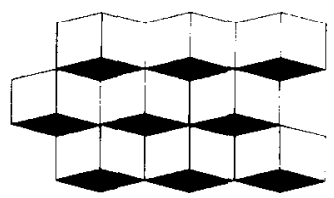

After coalescence
Fig. 1. Polymer particles before and after complete deformation.

mer molecules diffuse across the boundary and remove the last traces of the original boundaries [1-3]. In order to avoid confusion we will use in this article the term particle deformation instead of the first stages of the total coalescence process.

Over the years particle deformation has received widespread attention resulting in a large number of papers [49]. Deformation is an essential part of the film formation of latex based coatings because it results in a reduction of the size and the amount of voids within the film and, thus, in a reduction of the amount of scattered light. In this article, a critical review of the research published on latex film formation will be presented. In Section 2 the main theories are discussed, while Section 3 deals with the consequences of these theories regarding specific parameters; such as temperature and particle radii.

\section{Overview of the deformation theories}

\subsection{Dillon, Matheson and Bradford [4]}

In 1951 Dillon et al. [4] published one of the first papers concerning film formation of latex based coatings. Their theory was based on the investigations conducted by Frenkel [10] who had studied the viscous creep inside crystalline bodies. According to him the main force that leads to the formation of a contact area between two adjoining particles is the surface tension of these particles; reduction of the overall surface area is energetically favourable. A schematic representation of two adjoining crystalline bodies is given in Fig. 2. The angle $\Theta$ is called the angle of deformation. He derived the following relationship between the angle of deformation $\Theta$, the particle radius $R$ and the time $t$ :

$\Theta^{2}=\frac{3}{2 \pi} \frac{\sigma}{R \eta} t$

In this equation the polymer surface tension is depicted by $\sigma$ and the polymer viscosity by $\eta$. From the magnitude of the angle $\Theta$ information can be obtained about the extent of deformation; c.g. with complete deformation, the angle of deformation will be $30^{\circ}$. Eq. (1) was used by Dillon et al. [4] to describe the deformation part of film formation. To make sure that Frenkel's equation is applicable in the case of polymer particles suspended in water, Dillon et al. measured the angle of deformation of coagulated particles in water for various particle radii. Their results showed an accurate correlation hetween theory and experiments. On the basis of these experiments they concluded that the polymer surface tension is the main driving force for particle deformation. However, the following remarks should be made:

(i) the experiments were carried out in very dilute latexes and not in latexes usually encountered in coatings;

(ii) the polymer particles were assumed to be viscous, although, in reality, they are visco-elastic;

(iii) in the experiments of Dillon et al., only polymer/ water interfaces are involved, while in drying films polymer/air and water/air interfaces may also be important.

\subsection{Brown [5]}

In 1956 Brown [5] published an article that had tremendous influence on the development of film formation theories. In this article, he presented an overview of the practical findings that conflict with the assumptions of the previous theory of Dillon et al. These findings are as follows.

(i) Film formation occurs at progressing water evaporation and both processes finish simultaneously while the theory of Dillon et al. does not take into account the influence of the water/air interface.

(ii) A film dried at a temperature below the MFFT results in a porous, opaque film. When the temperature is subsequently raised to above the MFFT, the film properties do not change. Note that considerable doubt has been cast on this statement by the work of Sperry et al. [11] who discovered that those films do gain some transparency after prolonged time.

(iii) Slightly crosslinked latexes may still form a continuous film, although viscous flow, a necessary condition according to Frenkel, is no longer possible in that case.

Brown proposed an alternative model to replace Dillon's model [4]. It consists of the following steps:

(i) the latex is applied onto the substrate;

(ii) water evaporates from the bulk; the solids concentration increases;

(iii) the polymer particles are no longer mobile at a

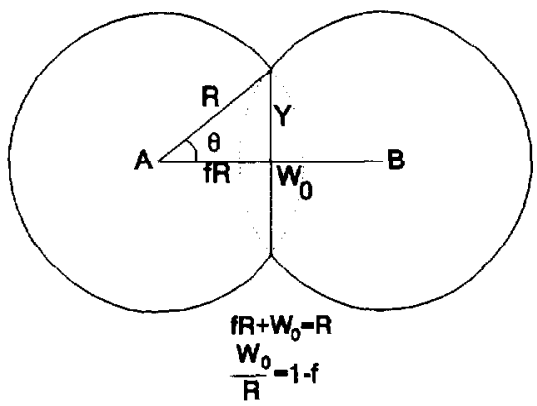

Fig. 2. Schematic representation of the two bodies pressed together according to Frenkel [10]. 
volume fraction close to 0.74 and are packed in ordered arrays;

(iv) the water evaporates from the interstices between the polymer particles; the evaporation leads to a water/air interface that recedes from the surface of the film. The water/air surface tension results in a compression of the particle packing. According to Brown, the polymer particles deform due to these interparticle forces, provided the temperature is above the MFFT.

We shall mainly focus here on the deformation part of Brown's model. The objective of his approach was to define which parameters control the extent of deformation of a polymer particle. He stated that for the polymer particles to deform, the forces promoting deformation must be larger than those opposing it. He examined the various forces involved and divided the forces into two categories; those promoting deformation and those opposing deformation (Fig. 3). This leads to the following condition for deformation:

$F_{\mathrm{S}}+F_{\mathrm{C}}+F_{\mathrm{V}}+F_{\mathrm{g}}>F_{\mathrm{G}}+F_{\mathrm{e}}$

For complete deformation to be achieved this condition must be maintained throughout the process. Since some of these forces are relatively small, not all the forces have to be taken into account, changing condition (2) into:

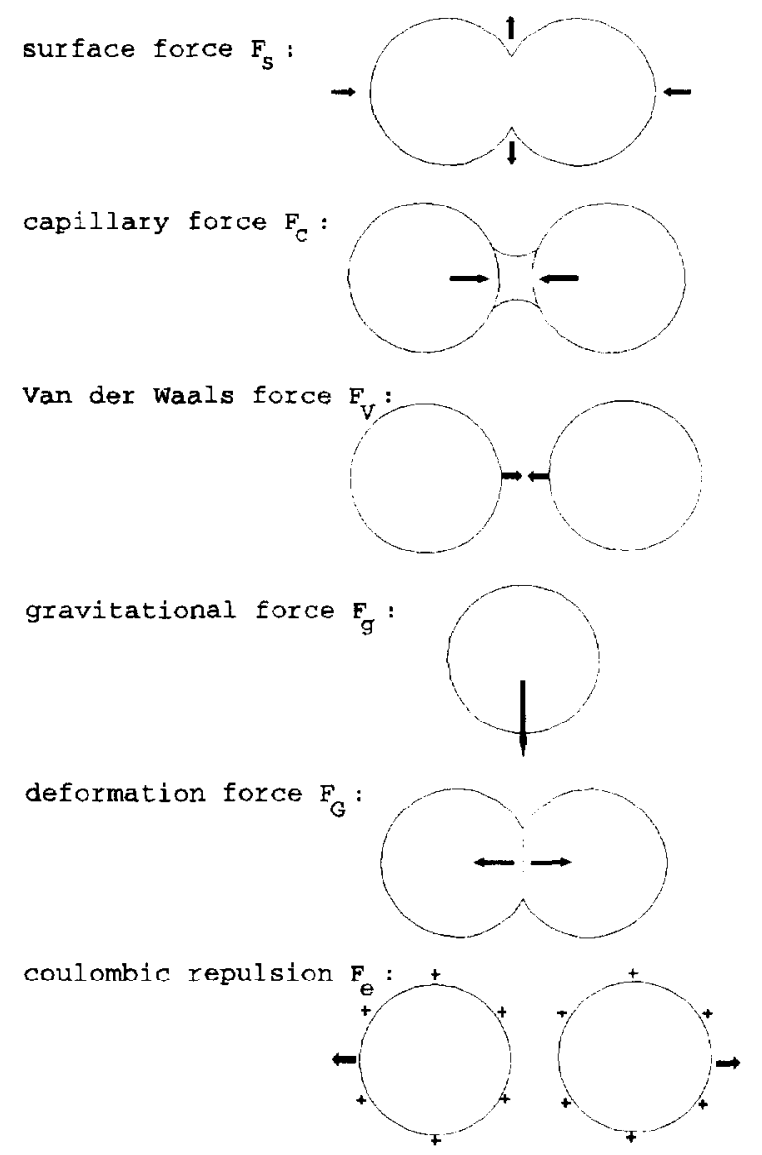

Fig. 3. A schematic representation of the forces acting on the polymer particles.
$F_{\mathrm{C}}>F_{\mathrm{G}}$

Subsequently, he assumed that the areas on which the capillary and the deformation force acts are roughly the same, resulting in the following condition for the associated pressures:

$P_{\mathrm{C}}>P_{\mathrm{G}}$

In order to derive an expression for the capillary pressure due to the receding water/air interface Brown used the following approximation [12] (capillary pressure $P_{\mathrm{C}}$, water/air surface tension $\sigma_{w / a}$ and the polymer particle radius $R$ ):

$P_{\mathrm{C}}=12.9 \frac{\sigma_{\mathrm{w} / \mathrm{a}} \cos \alpha}{R}$

where the contact angle $\alpha$ is defined as the angle of the three-phase contact line between the water/air interface and the polymer particle. Brown supposed $\alpha$ to be equal to $0^{\circ}$ and, thus, we shall leave the $\cos \alpha$ term out. Lin and Meier [13,14] stated that Eq. (5) does not lead to the correct value for the capillary pressure, since this approximation corresponds to the excess pressure inside an air bubble that would just fit into the space bounded by three contacting polymer particles with radius $R$. However, experiments performed by Mason and Morrow [15] reveal that this approximation is, within $10 \%$ accuracy, in agreement with experimentally obtained data (11.07 instead of the dimensionless factor 12.9 from Eq. (5)).

In order to model the response of the polymer particle to deformation Brown assumed the polymer particles to be smooth, elastic spheres. He applied the contact theory of Hertz $[16,17]$ for elastic bodies. Using this theory one can obtain an analytical solution for the magnitude of the contact area formed when two elastic spheres are pressed together and for the resulting pressure distribution. In that case, the pressure $P_{\mathrm{G}}$ averaged over the contact area, is given by:

$P_{\mathrm{G}}=0.37 G$

where $G$ is the shear modulus of the polymer particles.

Combining expressions (5) and (6), condition (4) changes into:

$G<35 \frac{\sigma_{\mathrm{w} / \mathrm{a}}}{R}$

From this condition he concluded that for film formation to occur, the shear modulus $G$ has to be smaller than $35 \sigma_{\mathrm{w} / \mathrm{i}} / R$. If the modulus is above this critical value, film formation should not take place. However, it should be emphasized that due to the serious limitations of Brown's model, Eq. (7) can merely act as a guideline whether film formation may occur or not. Finally, there are two assumptions in Brown's model that are not justified:

(i) the areas on which the capillary and the deformation forces act, are equal;

(ii) the polymer particles are purely elastic. 


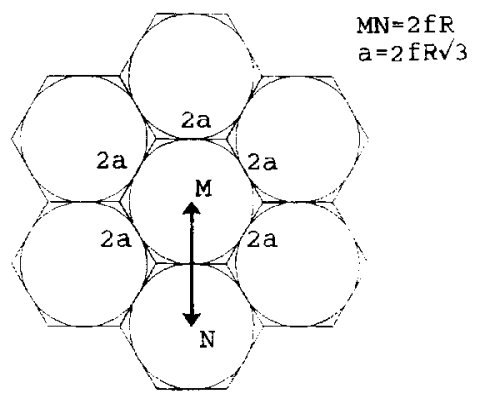

Fig. 4. Polymer particles with radius $f R$. close packed in an array of regular hexagons.

\subsection{Mason [7]: correcting for assumption (i) in Brown's model}

Assumption (i) of Brown's model was addressed by Mason [7] who corrected Brown's model by comparing the capillary and deformation forces instead of the associated pressures. Like Brown, he stated that the main driving force for particle deformation consists of the curved water/air interface receding into the layers of polymer particles. Furthermore, it is the particle at this interface pulled down by the capillary forces onto the underlying particles that causes them to deform. For undeformed partucles, the vertical force exerted by the top particle was taken to be:

$F_{\mathrm{n}}=\pi R^{2} P_{\mathrm{C}}$

where the capillary pressure is defined as in Eq. (5). Since during film formation the cross section of a particle changes from circular to hexagonal. the area on which the capillary pressure acts, changes accordingly. He assumed that the particles could be regarded as regular hexagons (Fig. 4). He defined the distance between the two centres as being equal to $2 / R$. The parameter $f$ is a correction for the extent of deformation; e.g. $f$ equals 1 in the absence of deformation and $f$ reaches a value of 0.905 in the case of complete deformation. Furthermore, Mason. assumed that the area on which the capillary pressure acts equals the area given by the regular hexagon. Combining both assumptions leads to the following equation for the force $F_{\mathrm{n}}$ :

$F_{\mathrm{n}}=2 f^{2} R^{2} \sqrt{3} P_{\mathrm{C}}$

Assuming face centred cubic packing, this force is distributed over the three underlying particles. The force exerted by the top particle normally onto each of the underlying particles, is given by:

$F_{\mathrm{C}}=\sqrt{2} f^{2} R^{2} P_{\mathrm{C}}$

In order to derive an expression for the deformation force $F_{\mathrm{G}}$, Mason used the Hertz theory [16,17] and obtained the following expression for the deformation force:
$F_{\mathrm{G}}=\frac{16}{3} \sqrt{2} G R^{2}(1-f)^{3 / 2}$

By inserting Eqs. (10) and (11) into condition (3) he derived the following criterion for complete particle deformation:

$G<67.6 \frac{\sigma_{\mathrm{w} / \mathrm{a}}}{R}$

Since the capillary force does not remain constant during deformation, he derived also a corrected criterion:

$G<266 \frac{\sigma_{\mathrm{w} / \mathrm{a}}}{R}$

In conclusion, it should be emphasised that, like Brown, Mason used the Hertz theory. Although Mason, in his discussion, notes the possibility of some plasticity, in his model the particles are supposed to be purely elastic. This implies that once the main force is removed, i.e. the water evaporation is complete, the polymer particles would resume their original spherical form. Since this has not been observed in practice, the elastic behaviour of the particles should be questioned, unless there is some other force holding the particles together after complete removal of water from the film, i.e. the interdiffusion of polymer chains across the particle boundaries $[1-3]$ or the polymer/air surface tension.

\subsection{Lamprecht [6]: correcting assumption (ii) in Brown's model}

Lamprecht [6] addressed assumption (ii) in Brown's model by developing an alternative model in which he assumed the polymer particles to be visco-elastic. He used the contact theory developed by Yang [18] in order to obtain an expression for the radius, $a$, of the contact area in the case of two linear visco-elastic spheres pressed together:

$a^{3}(t)=\frac{3 R}{16} \int_{-\infty}^{t} J(t-\tau) \frac{\mathrm{d} F_{C}(t)}{\mathrm{d} \tau} \mathrm{d} \tau$

where $J(t)$ is the creep compliance of the material and $F_{C}(t)$ is the force as defined by Mason [7]. The basic idea behind Lamprecht's model is that, using this expression, one is able to calculate the radius of the contact arca as a function of time. Since the particles are deformed into dodecahedra, one can derive the magnitude of the contact radius at complete deformation to be: $a^{3}=0.0835 R^{3}$. Furthermore, he stated that for successful deformation to occur, the calculated contact area after complete drying should be at least equal to or larger than the contact area in the case of complete deformation. Using this approach he derived the following criterion in the case of constant force:

$\frac{1}{J\left(t_{\text {drying }}\right)} \leq 95 \frac{\sigma_{\mathrm{w} / \mathrm{a}}}{\mathrm{P}}$ 
The Lamprecht model is a generalisation of the BrownMason model and, therefore, Eq. (15) should yield the solution of the Brown-Mason model in the case of purely elastic spheres pressed together under constant capillary pressure $(1 / J(t)=G)$. Evaluation of Eqs. (12) and (15) shows a remarkable difference in the prefactor (95 instead of 67.6). This is due to a flaw in the Brown-Mason model; for purely elastic bodies the radius of contact should be derived from the Hertz theory instead of purely geometrical considerations. This yields for the contact radius $a^{2}=(1-f) R$, instead of $a^{2}=2(1-f) R$ found by Brown. This was first corrected by Lamprecht. The criticism of Eckersley and Rudin [9] of this correction was without argumentation and unjustified.

It should be realised that the extent of deformation is of such a degree that it is no longer justifiable to assume linear visco-elasticity. In reality the particle will show considerable non-linear visco-elastic behaviour. Up till now, there are no analytical theories regarding particle deformation that take non-linearity into account. The approach of Lamprecht is certainly an advance, but it does not as yet include this deviation from linearity.

\subsection{Kendall and Padget [19]: a model based on the JKR theory}

Both Brown [5] and Mason [7] made use of the Hertz theory to describe the deformation. To do so, they had to assume that the polymer particles are purely elastic. This approach leads to serious difficulties when considering the situation after removing the force that promotes deformation. Kendall and Padget used an alternative theory to describe deformation; the JKR theory [20,21]. In contrast to the Hertz theory the JKR theory gives an expression for the radius of the contact area in the presence of an effective attraction between two elastic spheres. In the case of attraction, even when there is no external load pressing the particles together, there is still a deformation caused by the internal van der Waals attraction between the particles. Johnson, Kendall and Robertson, the founders of the JKR theory, called such particles 'sticky solids'. They' derived the following relationship between the radius $a$ of the contact area and the applied load $W(E$ the Young modulus, $v$ the Poisson's ratio and $R$ the radius of the particles):

$a^{3}=\frac{3}{4}\left(1-\nu^{2}\right) \frac{R}{E}\left[W+\frac{3}{2} \pi R \gamma+\sqrt{3 \pi R \gamma W+\left[\frac{3}{2} \pi R \gamma\right]^{2}}\right]$

The parameter $\gamma$ is called the surface energy and is defined as the energy released when two surfaces of unit area move into proximity. Since Johnson, Kendall and Roberts do not specify the mechanism by which this energy is released, the surface energy cannot be calculated a priori and must be obtained by fitting Eq. (16) to experi- mental data. However, Israelachvili [22] proposed to take for the interfacial energy $\gamma$ twice the solid/vapour interfacial tension $\sigma_{\mathrm{sv}}$. Roberts and Tabor [23] found that the JKR theory adequately describes the deformation of smooth rubber spheres (typical diameter: $4 \mathrm{~cm}$ ) in dry contact with a rubber flat.

Kendall and Padget [19] used the JKR theory to describe the deformation of spheres in the film formation of a latex. Their approach consists of calculating the magnitude of the contact area after complete removal of water; therefore, there is no external load left pressing the particles together. In that case, the radius of the contact area given by Eq. (16), changes into:

$a^{3}=\frac{9}{4} \pi\left(1-v^{2}\right) \frac{R^{2} \gamma}{E}$

They have tested the applicability of this equation by measuring the diameter of the contact area by means of electron microscopy using very diluted latexes. Their results showed a good correlation with the values predicted by the JKR theory. After checking Eq. (17), experimentally, they stated that for complete film formation, all the pores present in the film must disappear. They distinguished two kinds of pores in a close packed hexagonal array of polymer particles: triangular and cubic pores (Fig. 5). For the triangular pores just to disappear, the size of the contact areas must be half the sphere diameter. Inserting this requirement into Eq. (17) one obtains for the Young modulus:

$E \leq 18 \pi\left(1-\nu^{2}\right) \frac{\gamma}{\mathrm{P}}$

For the cubic pores just to disappear, the size of the contact areas has to equal the sphere diameter. Inserting this requirement into Eq. (17):

$E \leq \frac{9 \pi\left(1-\nu^{2}\right)}{4} \frac{\gamma}{\mathrm{P}}$

For complete deformation to be achieved the Young modulus must be smaller than the value obtained from Eq. (19). Note that, in reality, the particles depicted in Fig. a
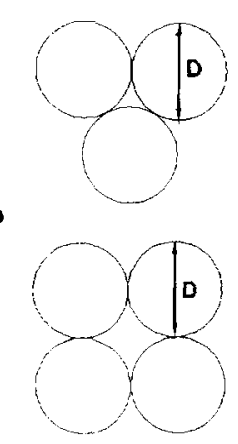

c

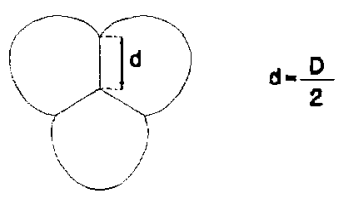

d

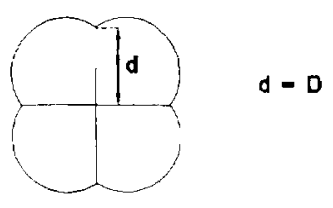

Fig. 5. Triangular (a) and cubic (b) pores in a film before deformation: triangular (c) and cubic (d) arrangements after complete deformation. 
5 have more neighbouring particles than drawn. The influence of those particles on the value of the diameter $D$ was not taken into account by Kendall and Padget. Furthermore, it should be noted that the onset of clarification of the latex film which is usually defined as the transition between a non-film forming and a film forming latex, and the moment of complete closure of the triangular and cubic pores, do not coincide; a reduction in the size of the pores lowers the scattering capability of the pores and, consequently, the film clarifies although complete closure of the pores has not yet occurred.

\section{Influence of specific parameters on film formation}

In the previous section we have described five models in order to explain the deformation of the polymer particles during film formation. In this section we will examine whether any of these five models can explain some basic characteristics of latex based coatings.

\subsection{Influence of temperature}

As mentioned in Section 1, an important characteristic of latex-based coatings is the MFFT which can be measured by an apparatus developed in 1960 by Protzman and Brown [24]: the MFFT bar. This is basically a bar with a fixed temperature gradient along its length, on the surface of which a film is being dried. Experiments performed using this apparatus have shown that the transition temperature between non-film forming and film forming conditions is a sharp, distinct one. Furthermore, experiments have shown that the difference between the MFFT and the glass transition temperature of the polymer particles used is only a few degrees. The five models described in the previous section should explain both findings, if they accurately describe film formation. Examination of Eqs. (1).

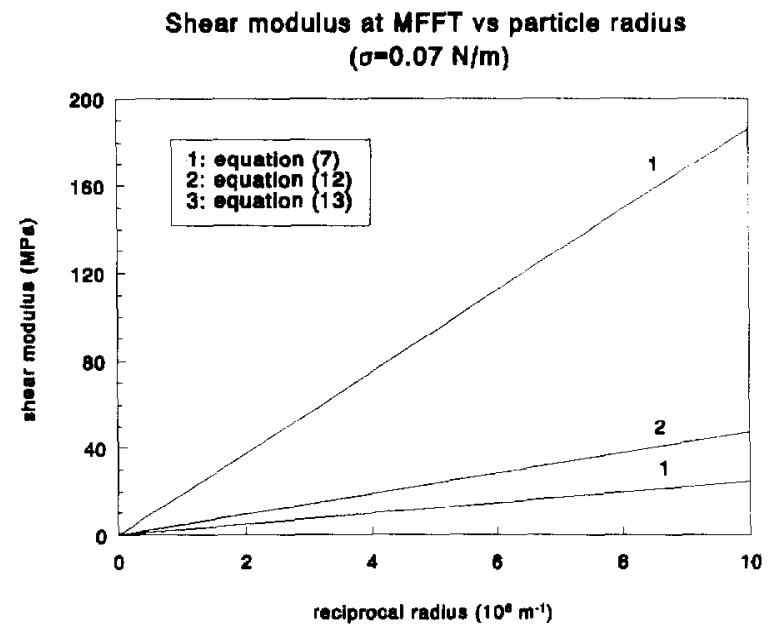

Fig. 6 . The linear relationship between the critical shear modulus and the reciprocal particle radius according to Eqs. (7). (12) and (13).

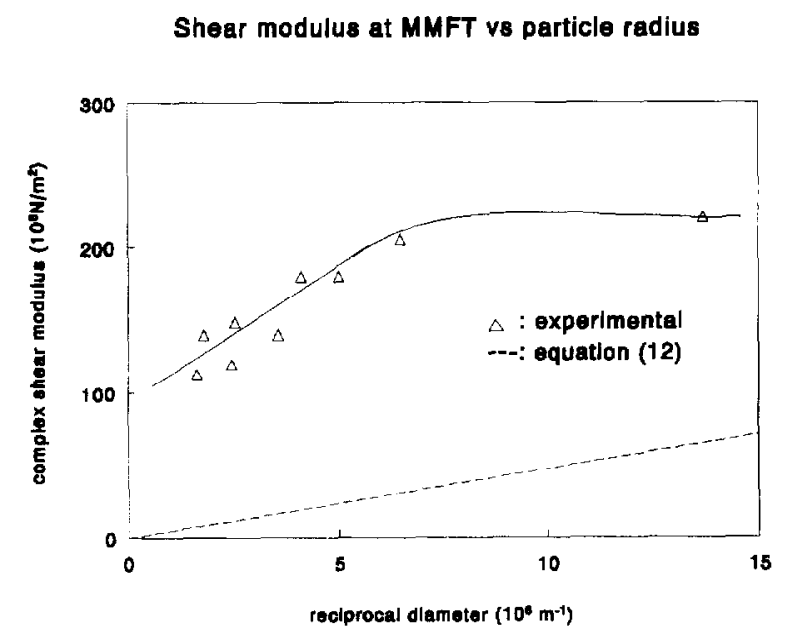

Fig. 7. Results by Eckersley and Rudin [9] for a methyl methacrylate/ butyl acrylate copolymer compared with the predictions by the model of Mason.

(7), (12), (13) and (19) reveals that there is no explicit temperature dependence for all five models. However, there is still an implicit dependence via the mechanical behaviour of the polymer particles; the mechanical behaviour appears in all five equations in the form of the shear modulus or a closely related property. It is known that the mechanical behaviour of an amorphous polymer shows a sharp decrease in the shear modulus over several decades at the temperature, normally referred to as the glass transition temperature $T_{\mathrm{g}}$. In conclusion, all five models give an explanation for the existence of a sharp transition point for film formation, the MFFT, by relating it to the sharp change of the elastic modulus near the glass transition temperature.

\subsection{Influence of the particle size}

An important tool in controlling the final film properties is the diameter of the polymer particles in the latex-based coating. Examination of Eqs. (1), (7), (12), (13) and (19) reveals that all five models predict a reversed proportionality between the extent of deformation and the particle radius (Fig. 6). From Fig. 6, one may conclude that using a latex consisting of small particles, higher $G$ moduli are permitted, still resulting in transparent, homogeneous films.

In 1990 Eckersley and Rudin [9] published their results concerning the film formation in the case of methyl methacrylate/butyl acrylate copolymers. They mcasurcd the MFFT of latexes with different radii using the apparatus devcloped by Protzman and Brown [24]. Furthermore, they also measured the dynamic shear modulus of the final, dry polymer film at the MFFT and compared these with the predictions using Mason's model (Eq. (12)). Their results, as depicted in Fig. 7, reveal that the critical elastic modulus is a linear function of the reciprocal particle diameter, especially in the range of $10^{6}$ to $6 \times 10^{6} \mathrm{~m}^{-1}$. The 
single data point obtained for smaller particles suggests that there is a plateau at higher reciprocal diameters. Furthermore, extrapolation of these same results suggests that for infinitely large particles the elastic modulus just permitted for film formation has a non-zero value. This conflicts with the theories presented in Section 2. In their original article [9] they concluded that the approach followed by Brown was incorrect since they found polymer films formed while the shear moduli were above the permitted values as obtained from Eq. (12). In our opinion, this can be explained from the fact that they measured the shear moduli of the dry films assuming that these were equal to those during deformation; i.e. water does not lower the shear modulus $G$. However, it has been known for a long time that water can have a serious influence on the mechanical behaviour of polymers. Experiments performed by Brodnyan and Konen [25] on the film formation of an ethyl acrylate/methyl methacrylate copolymer, show that the presence of water in the film lowers the shear modulus by a factor 10 . If this would also apply to the latexes used by Eckersley and Rudin [9], the $G$ moduli would have been much lower and possibly ended up below the theoretical line given by Eq. (12).

Apart from the problems associated with the determination of the shear moduli, another problem is the unexpected effect of the particle diameter on measurements performed with the method of Protzman and Brown. This was a point which had been realised in industry for many years, but was first put in print by van Tent [26]. This effect is entirely due to the fact that the Protzman-Brown method is based on the visual determination of the transition between the transparent and the opaque region of the film and that, consequently, the capability of the voids to scatter light determines whether particle deformation is detectable or not by visual observation. A useful parameter to characterise the amount of light scattering is the turbidity $\tau_{5}$ of the latex film. The turbidity is linked to the transmission of light through a latex film of thickness $l$ via the following expression:

$\frac{I}{I_{0}}=\exp \left(-\tau_{\mathrm{s}} l\right)$

where $I$ and $I_{0}$ are respectively the intensity of the light after and before passage through the latex film. Assuming Rayleigh scattering, the turbidity can be expressed relative to the volume fraction as:

$\tau_{\mathrm{s}}=\frac{24 \pi^{3} n_{\mathrm{m}}}{\lambda_{0}^{4}}\left[\frac{m^{2}-1}{m^{2}+2}\right]^{2} v_{\text {void }} \phi_{v}$

where $n_{\mathrm{m}}$ and $n$ are respectively the refractive index of the surrounding medium and of the voids, $m$ is the relative refractive index $\left(n / n_{\mathrm{m}}\right), \lambda_{0}$ is the wavelength of light in vacuum, $\phi_{v}$ is the volume fraction voids and $v_{\text {void }}$ is the volume of a void. This volume can expressed as relative to the volume of a particle $v_{\text {particle }}$ as: $v_{\text {void }}=\phi_{v} v_{\text {particle }} \frac{N_{\text {particle }}}{N_{\text {void }}}$

where $N_{\text {void }}$ and $N_{\text {particle }}$ are respectively the number of voids and the number of particles. In the case of a faced centre cubic packing, there is one octahedral void per particle. We distinguish two different states; i.e. when the voids consist of dry air $(n=1.00)$ and when the voids consist of water $(n=1.33)$. The results of our calculations listed in Table 1 reveal that there are large differences in transmission at identical volume fractions but at different particle radii; e.g. when particle deformation has proceeded to such an extent that the volume of the film contains $1 \%$ air voids, $97 \%$ of the light is transmitted in the case of $100 \mathrm{~nm}$ particles, while it is only $4 \%$ in the case of $500 \mathrm{~nm}$ particles. Although the extent of deformation is identical, the film consisting of $100 \mathrm{~nm}$ particles would appear to be transparent, while the $500 \mathrm{~nm}$ film would be opaque. Our results also show that the amount of light scattering in the case of wet films is much more reduced compared to the scattering of a dry film; i.e. the extent of deformation has to exceed further in the case of dry films to obtain transparency. Furthermore, the transition between high and low transmission is sharper for larger particles; i.e. visual observation of the opaque/ transparent transition would be more reliable in the case of large particles, since small particles show a relatively long transition region. Thus, although the more elaborate Mie theory should be used to describe light scattering, our calculations give a first indication of the fact that the visual determination of the MFFT should be used with care when comparing different films (wet and dry films or small and large particles).

Although commercially available latex coatings have quite broad particle size distributions, most research has traditionally been focused on film formation of monodis-

Table 1

Transmission of light through a film of thickness $0.1 \mathrm{~mm}$ for various particle radii; the voids are composed of (a) air $\left(n_{\mathrm{m}}=1.5, n=1\right.$; $\left.\lambda_{0}=550 \mathrm{~nm}\right)$; (b) water $\left(n_{\mathrm{m}}=1.5, n=1.33 ; \lambda_{41}=550 \mathrm{~nm}\right)$

\begin{tabular}{lllllll}
\hline $\begin{array}{l}\text { Particle } \\
\text { radius }(\mathrm{nm})\end{array}$ & \multicolumn{6}{l}{ Volume fraction voids } \\
\cline { 2 - 7 } & 0.1 & 0.08 & 0.06 & 0.04 & 0.02 & 0.01 \\
\hline (a) & & & & & & \\
500 & 0.00 & 0.00 & 0.00 & 0.00 & 0.00 & 0.04 \\
400 & 0.00 & 0.00 & 0.00 & 0.00 & 0.00 & 0.18 \\
300 & 0.00 & 0.00 & 0.00 & 0.00 & 0.06 & 0.49 \\
200 & 0.00 & 0.00 & 0.00 & 0.03 & 0.43 & 0.81 \\
100 & 0.07 & 0.18 & 0.39 & 0.67 & 0.90 & 0.97 \\
& & & & & & \\
(b) & & & & & & \\
500 & 0.00 & 0.00 & 0.00 & 0.00 & 0.22 & 0.67 \\
400 & 0.00 & 0.00 & 0.00 & 0.05 & 0.46 & 0.82 \\
300 & 0.00 & 0.00 & 0.05 & 0.27 & 0.72 & 0.92 \\
200 & 0.09 & 0.21 & 0.42 & 0.68 & 0.91 & 0.98 \\
100 & 0.74 & 0.83 & 0.90 & 0.95 & 0.99 & 1.00 \\
\hline
\end{tabular}


Table 2

The difference between $\mathbf{T}_{\mathfrak{g}}$ and MFFT of different polymers are taken from the literature

\begin{tabular}{|c|c|c|c|c|}
\hline $\begin{array}{l}\text { Polymer } \\
\text { (composition) }\end{array}$ & $\begin{array}{l}\text { Particle diameter } \\
(\mathrm{nm})\end{array}$ & $\begin{array}{l}\text { MFFT } \\
\left({ }^{\circ} \mathrm{C}\right)\end{array}$ & $\begin{array}{l}\mathrm{T}_{\mathrm{E}} \\
\left({ }^{\circ} \mathrm{C}\right)\end{array}$ & $\begin{array}{l}\text { MFFT- } T_{z} \\
\left({ }^{\circ} \mathrm{C}\right)\end{array}$ \\
\hline $\begin{array}{l}\text { Styrene/butyl acrylate [25] } \\
(75: 25)\end{array}$ & 48 & 58 & 48 & +10 \\
\hline $\begin{array}{l}\text { Styrene/butyl acrylate [25] } \\
\quad(55: 45)\end{array}$ & 70 & 23 & 17 & +6 \\
\hline $\begin{array}{l}\text { Ethyl acrylate/methyl methacrylate [25] } \\
(50: 50)\end{array}$ & 68 & 27 & 30 & -3 \\
\hline $\begin{array}{l}\text { Butyl acrylate/styrene [11] } \\
\quad(35: 64)\end{array}$ & 530 & $50^{a}$ & 48 & +2 \\
\hline $\begin{array}{l}\text { Butyl acrylate/methyl methacrylate [11] } \\
(37: 62)\end{array}$ & 430 & $33^{a}$ & 44 & -11 \\
\hline $\begin{array}{l}\text { Butyl methacrylate/methyl methacrylate [11] } \\
(84: 15)\end{array}$ & 540 & $5 t^{3}$ & 50 & +1 \\
\hline $\begin{array}{l}\text { Butyl methacrylate [11] } \\
\qquad(100: 0)\end{array}$ & 565 & $32^{\prime \prime}$ & 36 & -4 \\
\hline
\end{tabular}

On the basis of group contributions [43] the ranking of the different polymers with respect to hydrophilicity is:poly(styrene) < poly(butyl methacrylate) $<$ poly(methyl methacrylate) < poly(butyl acrylate) < poly(methyl acrylate)

a'Measured after $0.1 \mathrm{~h}$.

perse polymer particles. There is, however, quite a new and interesting approach to film formation: the use of bimodal latexes $[9,27,28]$ in order to improve the final film properties. It is unknown as yet whether this is due to stimulated deformation of the larger particles in the presence of smaller particles [28] or to the formation of a co-continuous matrix in which the small particles are placed in the interstices bounded by the larger particles [27].

\subsection{Influence of water}

As already mentioned Brown was one of the first to point out the special role of water during film formation. According to him water evaporation is the main driving force for the deformation of the spherical particles into dodecahedrons. Since then many researchers have attempted to reveal the role of water during deformation.

Both Sheet< [29] and Dobler et al. [30,31]. approached this problem by studying the compaction of large agglomerates of polymer particles in the absence of a curved water/air interface. They found that after raising the temperature to above the MFFT, the solids content in the agglomerate increases to 84.8 vol.\% [29] or to $94 \mathrm{vol} \% \%$ [30]. Evidently, this increase cannot be due to the water/air surface tension as a driving force for particle deformation. In our opinion, it is the polymer/water interfacial tension in this case that deforms the polymer particles leading to a reduction of voids. However. it should be mentioncd that, although considerable deformation has certainly taken place, the solids content in both investigations did not attain the levels normally encountered in coatings. approximately $100 \%$. Dobler et al. claimed in a later publication [31] that although the particle/water interfacial tension is capable of deforming the particles, the water/ air surface tension is the main driving force under 'normal' circumstances.

Apart from Sheetz and Dobler et al., there is still another interesting approach to this subject. According to Brown's third point of criticism on Dillon's work, it should be impossible for film formation to occur by raising the temperature after the film is completely dried below the MFFT. This experiment has been carried out by Sperry et al. [11] who applied latex onto a cold MFFT bar. After complete water evaporation the MFFT bar was activated and a temperature gradient was created. Since water evaporation could no longer take place, deformation should not occur. However, a transparent region at the heated end of the bar appeared suggesting that deformation had occurred. The visible transition between the two regions enabled Sperry to measure the 'dry MFFT'. Furthermore, he found that the films tended to clarify with time; i.e. MFFT is a function of time. Note that this suggests the response of the polymer particles to deformation to be visco-elastic. In order to obtain a better proof, Sperry measured the dry MFFT and the wet MFFT in the cases of hydrophobic and hydrophilic copolymers. His results indicale that there is no difference between the two MFFTs in the case of the hydrophobic latex. However, in the case of the hydrophilic copolymer there is a distinct difference. Sperry et al. concluded from this that there is no need to invoke special water driven forces to explain deformation, especially in the case of hydrophobic latexes.

These three investigations have not delivered conclusive proof to dismiss the idea of the special role of water' in generating capillary forces. To a certain cxtent compaction appears to proceed both in the absence and in the presence of water evaporation. Differences in the extent of deformation in both cases may be explained from the plasticising effect of water on the polymer parti- 
cles, especially in the case of the hydrophilic latexes; i.e. both the water/air, the polymer/water or the polymer/air interfacial tension may be strong enough to cause particle deformation, but the decrease of the elastic modulus due to the presence of water governs the extent of deformation.

\section{Concluding remarks on particle deformation}

As mentioned before, the deformation step in film formation has received widespread attention over the years resulting in a large number of publications. There is, however, still some controversy about the mechanism of deformation. The main point of controversy concerns the driving force for film formation; the alternatives range from the various interfacial tensions to Kendall and Padget's unspecified surface energy $\gamma$. Although different models have been proposed, the one that has received the most attention assumes water evaporation to be the main cause of particle deformation. According to this approach the main driving force is supplied by the water/ air interface receding into a close packing of polymer particles. The resulting force exerted by the top layer of particles on the particles below causes them to deform. The experiments performed by Sperry et al. have shown that particle deformation is also possible in the absence of water evaporation. We would not go as far as to advocate that capillary pressures have no role whatsoever during deformation. It is very likely that capillary pressures do play an important role. However, those capillary pressures may not be caused by the receding water/air interface, but by residual water left between the particles after drying. This water forms bridge-like structures between the particles and causes the particles to be pressed together.

We think that water evaporation proceeds until the water/air interface has receded to about the equatorial plane between the particles in the top layer. Under such conditions they most effectively press the underlying particles together. If drying proceeds without sufficient particle deformation, the interface will recede further. This retraction is composed of local jumps to underlying equatorial planes ('Ilaines jumps'). During this process, some water is left at the contacts between the particles, forming liquid bridges.

Schubert [32] has performed some calculations on the force acting between two particles connected by such a liquid bridge. His computer calculations show that the pressure associated with such bridges can be more than sufficient for deformation to occur: the pressure can become negative and amount to $-10^{7} \mathrm{~Pa}$. Sperry's experiments show that deformation is also possible in the absence of a receding interface. This suggests that the research should also include the deformation due to the liquid bridges. Recently, Keddie et al. [33] proposed a new model for particle deformation: an 'easy' route along which the particles deform due to the capillary forces generated by the curved water/air interface at the film surface and a 'hard' route along which the particles deform due to other surface forces (e.g. due to the polymer/water interfacial tension, the polymer/air surface tension or the liquid bridges). Using ellipsometry, they found indications of these two separate routes to obtain a transparent, homogeneous film. The findings of Sheetz [29], Dobler [30,31] and Sperry [11] can now be incorporated into a film formation model as particle deformation along the 'hard' route.

Apart from generating the capillary pressure necessary for deformation another function of water can be the plasticisation of the polymer particles. By plasticising the polymer particles it becomes easier to deform the particles; i.e. there is less resistance to deformation. It is interesting to examine whether deformation occurs at lower temperatures in the situation of hydroplasticisation compared to the situation of no hydroplasticisation. Experiments that can test this assumption are difficult to imagine. However, the difference between the MFFT and the $T_{\mathrm{g}}$ for different hydrophilicities of the polymers involved can give a good indication of the influence of hydroplasticisation. Brodnyan and Konen [25] measured the MFFT and the $T_{\mathrm{g}}$ of both styrene/butyl acrylate copolymers and ethyl acrylate/ methyl methacrylate copolymers. They found that the MFFT of the more hydrophobic styrene/butyl acrylate copolymer was above the $T_{\mathrm{g}}$, in contrast to the more hydrophilic ethyl acrylate/methyl methacrylate copolymers that form films at a temperature below the $T_{\mathrm{g}}$. Although this is not conclusive evidence for the effect of hydroplasticisation, it suggests that the quantity (MFFT $-T_{\mathrm{g}}$ ) is partly defined by the hydrophilicity of the polymers. In Table 2 MFFT $-T_{\mathrm{g}}$ values from the literature are listed to illustrate the influence of hydrophilicity on this difference. The results from Brodnyan and Konen [25] show that increasing the hydrophilicity of the styrene/butyl acrylate copolymer results in a decrease in the MFFT compared to the $T_{\mathrm{g}}$. Similar results were obtained by Sperry et al. [11]; replacing butyl acrylate with the less hydrophile butyl methacrylate leads to an increase in the difference. However, there is no conclusive proof for the linking of (MFFT $-T_{\mathrm{g}}$ ) to hydrophilicity: e.g. the change from butyl methacrylate homopolymer to the more hydrophilic butyl methacrylate/methyl methacrylate does not result in a lowering of the difference, but even in a raising of this difference. Thus, more effort will have to be invested to clarify this point of controversy. Note that the MFFT is a function of time. Thus when using values of MFFT - $T_{\mathrm{g}}$ as a tool to characterise 'hydroplasticisation', these values should be compared at identical experimental time scales.

$\Lambda$ part from the polymer particles and the water phase, surfactants are an important component in latex-based coatings. Much research has been devoted to the fate of surfactants after application of the latex onto a substrate, either by electron microscopy $[34,35]$, direct energy trans- 
fer fluorescence [36] or Fourier transform infrared spectroscopy [37-41]. The most popular views nowadays are:

(i) the surfactant is retained at the polymer/polymer interface, thus leading to a hydrophilic network [1];

(ii) the surfactant migrates to the film/air and the film/ substrate interfaces $[34,35,42]$;

(iii) the surfactant concentrates in 'islands' within the film [42];

(iv) the surfactant migrates into the polymer particles, thus reducing the elastic modulus $[1,38]$.

Which of these four alternatives occur depends on the composition of the system studied. The three controlling parameters, are:

(i) the compatibility: the interaction between surfactant molecules and the polymer particles. In the case of low compatibility Evanson and Urban [37] found that the surfactant migrates to the film/air and the film/substrate surfaces while in the case of high compatibility migration is inhibited. This effect is attributed to surfactant penetration into the latex particles.

(ii) the strength with which the surfactant molecules are absorbed at the particle surface: in the extreme case of grafting, the surfactant molecules cannot migrate and remain at the particle surface hindering the diffusion of polymer chains across the boundaries.

(iii) the rate of evaporation: surfactant enrichment at the film/air surface may occur due to transport of water through the film to the film/air surface. If diffusion is slow compared to convection, no levelling of the surfactant concentration occurs resulting in an increase in surfactant concentration at the interface. This has been reported by Zhao et al. [42] who studied the surface of methyl methacrylate/butyl acrylate copolymer using $X$ ray photoelectron spectroscopy (XPS) and secondary ion mass spectrometry.

From the theoretical framework described in Section 2, one would expect that the reduction of the interfacial tension by the presence of surfactants would lead to a retardation of the deformation process. Furthermore, transport of surfactant out of the region between two approaching polymer particles may lead to a gradient in the interfacial tension and, therefore, to a slowing down of the deformation process (Maragoni flow). Plasticisation by the migration of surfactant into the polymer particle can lead to an increase in the extent of deformation. However, no experimental data exist that explicitly link the role of the surfactant to the extent of deformation.

Another problem in modelling the deformation is the mechanical response of the particles. The models of Brown [5], Mason [7] and Kendall and Padget [19] assume the particles to be elastic, while the model of Dillon et al. assumes a viscous response. The only model which attempts to take into account the visco-elastic behaviour of the particles is the model of Lamprecht [6]. In order to obtain a better understanding of the deformation the viscoelastic behaviour of the particles should be examined.
The models described in this article give only a partially correct view on the process of deformation of the polymer particles. Therefore, they can only serve as a good first order approximation. In order to obtain a better insight into the deformation step the different aspects of the deformation should be investigated in more detail; like the role of water and the surfactants present, the capillary pressure and the visco-elastic response.

\section{Nomenclature} $F$

$F_{\mathrm{C}}$

$F_{\mathrm{e}}$

$F_{\mathrm{g}}$

$F_{\mathrm{S}}$

$F_{\mathrm{V}}$

$G$

$J(t)$

$n$

$n_{\mathrm{rm}}$

$N_{\text {parricle }}$

$N_{\text {void }}$

$P_{\mathrm{C}}$

$P_{\mathrm{G}}$

$R$

$T$

$T_{\mathrm{g}}$

$v_{\text {purtick }}$

vold

W

Greek letters

$\alpha$
$\gamma$
$\eta$
$\Theta$
$\lambda$
$\nu$
$\sigma$
$\sigma_{\mathrm{w} / \mathrm{a}}$
$\tau$
$\tau_{\mathrm{s}}$
$\phi_{\mathrm{v}}$

contact angle (rad)

surface energy $(J)$

polymer viscosity (Pas)

angle of deformation (rad)

wave length in vacuum (m)

Poisson's ratio (-)

interfacial tension $\left(\mathrm{N} \mathrm{m}^{-1}\right)$

water/air surface tension $\left(\mathrm{N} \mathrm{m}^{-1}\right)$

time (s)

turbidity $\left(\mathrm{m}^{-1}\right)$

volume fraction voids (-)

\section{Acknowledgements}

We thank Dr John Geurts for his valuable discussions during the preparation of this paper.

\section{References}

[1] S.S. Voyutskiì, J. Polym. Sci., 125 (1958) 528. 
[2] E.B. Bradford and J.W. Vanderhoff, J. Mauromol. Chem., / (1966) 355.

[3] D. Distler and G. Kanig, Colloid Polym. Sci., 256 (1978) 1052.

[4] R.E. Dillon, L.A. Matheson and E.B. Bradford, J. Colloid Sci., 8 (1951) 108.

[5] G.L. Brown, J. Polvm. Sci., 22 (1956) 423

[6] J. Lamprecht, Colloid Polym. Sci., 258 (1980) 960

[7] G. Mason, Br. Polym. J., 5 (1973) 101.

[8] J.W. Vanderhoff, H.L. Tarkowski, M.C. Jenkins and E.B. Bradford. J. Macromol. Chem., I (1966) 361.

[9] S.T. Eckersley and A. Rudin, J. Coat. Technol., 62 (1990) 89.

[10] J. Frenkel, J. Phys. (Moscow), 9 (1943) 385.

[11] P.R. Sperry, B. Snyder, M.L. O Dowd and P.M. Lesko, Langmuir. $10(1994) 2169$

[12] P.C. Hiemenz, Principles of Colloid and Surface Chemistry, Marcel Dekker. New York, 1986

[13] F. Lin and D.J. Meier, Langmuir. // (1995) 2726.

[14] F. Lin and D.J. Meier, Proc. 21st Int. Conf. Org. Coat. Sci. Technol.. Athens, Greece, 1995, p. 297.

[15] G. Mason and N. Morrow, J. Colloid Interface Sci., 109 (1986) 46.

[16] H. Hertz, Gesammelle Werk, Vol. 92, Leipzig, 1895.

[17] L.D. Landau and E.M. Lifshitz, Theory of Elasticity, Pergamon. Oxford. 1970.

[18] W.H. Yang, J. Appl. Mech. (Trans. ASME), (1966) 395.

[19] K. Kendall and J.C. Padget, Int. J. Adhes. Adhes., 2 (1982) 149.

[20] K.L. Johnson, K. Kendall and A.D. Roberts, Proc. R. Soc. London. Ser. A, 324 (1971) 301.

[21] K. Kendall, Contemp. Phys., 21 (1980) 3.

[22] J. Israelachvili, Intermolecular and Surface Forces, Academic Press, London, 1991.

[23] A.D. Roberts and D. Tabor, Proc. R. Soc: London. Ser. A, 325 (1971) 323.

[24] T.F. Protzman and G.L. Brown. J. Appl. Polym. Sci., 4 (1960) 81.

[25] J.G. Brodnyan and T. Konen, J. Appl. Polym. Sci., 8 (1964) 687.
[26] A. van Tent, Ph.D. Thesis. University of Technology, Delft, 1992.

[27] J.M. Geurts, M. Lammers and A.L. German, Colloid Surf. A: Physiochem. Eng. Aspects, 108 (1996) 295.

[28] A.C.I.A. Peters, G.C. Overbeek, A.J.P. Buckmann, J.C. Padget and T. Annable, Proc. 2Ist Int. Conf. Org. Coat. Sci. Technol., Athens, Greece. 1995, p. 337.

[29] D.P. Sheetz, J. Appl. Polym. Sci., 9 (1965) 3759.

[30] F. Dobler, T. Pith, M. Lambla and Y. Holl, J. Colloid Interface Sci., 152 (1992) 1.

[31] F. Dobler, T. Pith, M. Lambla and Y. Holl, J. Colloid Interface Sci., 152 (1992) 12

[32] H. Schubert. Kapillaritat in porösen Feststoffensystemen, Springer, Berlin, 1982

[33] J.L. Keddie, P. Meredith. R.A.L. Jones and A.M. Donald, Macromolecules, 28 (1995) 2673.

[34] E.B. Bradford and J.W. Vanderhoff, J. Macromol. Chem., I (1966) 335.

[35] E.B. Bradford and J.W. Vanderhoff, J. Macromol. Sci., Phys. B, 6 (1972) 671 .

[36] S. Kawaguchi, E. Odrobina and M.A. Winnik, Macromol. Rapid Commun., 16 (1995) 861 .

[37] K.W. Evanson and M.W. Urban, J. Appl. Polym. Sci., 42 (1991) 2287.

[38] K.W. Evanson and M.W. Urban, J. Appl. Polym. Sci., 42 (1991) 2297.

[39] K.W. Evanson and M.W. Lrban, J. Appl. Polym. Sci., 42 (1991) 2309.

[40] T.A. Thorstenson, K.W. Fvanson and M.W. Urban, J. Appl. Polym. Sci.. 47 (1993) 1381.

[41] B.-J. Niu and M.W. Urban, J. Appl. Polym. Sci., 56 (1995) 377.

[42] C.L. Zao, F. Dobler, T. Pith, Y. Holl and M. Lambla, J. Colloid Interface Sci., 128 (1989) 437.

[43] D.W. van Krevelen, Properties of Polymers. Their Estimation and Correlation with Chemical Structure, Elsevier, Amsterdam, 1976. 